\title{
Torsional effects through mass asymmetry : A state-of-the-art review
}

\author{
Philip Luke $\mathrm{K}^{1}$, Robin Davis $\mathrm{P}^{2}$, Pradip Sarkar ${ }^{3}$ \\ 1, 2, 3 - Department of Civil Engineering, National Institute of Technology Rourkela, India, 769008
}

\begin{abstract}
Asymmetric distribution of mass over the floor slabs can cause torsional effects in buildings, even when it is symmetric in strength and stiffness. Such systems are referred to as mass eccentric or mass asymmetric buildings. Eccentricity in mass can result in building rotation in addition to its normally translation modes, which can further cause unpredictable deformation and even failure of the building under seismic loads. Irregularity in mass is found in buildings having concentrated mass elements in certain floors such as water tanks, machineries etc. Many researchers have attempted to study the behaviour of asymmetric buildings in general, but very few on the specific topic of mass asymmetry. This paper attempts to review and consolidate the literature written on the topic of mass asymmetry to the author's knowledge.
\end{abstract}

Keywords: RC buildings, Mass Eccentricity, Irregular Buildings, Asymmetry, Torsional Response

\section{Introduction}

Seismic loads are the most unwanted of all types of loads when setting out to design a building structure. This is because of the hazardous nature in which they can affect the structure and the fact that they cannot be predicted or prevented by any means. The only remedy a structural engineer can provide is to minimize the response the building shall undergo when it is laterally loaded with seismic excitation. This way, it can be ensured that the structure will have to show the minimal effects under light and moderate loadings and that it doesn't collapse under heavy loading.

Seismic response of a structure can be highly random in nature, resulting out of a number of reasons such as building geometry, material properties, loading pattern, mass distribution etc. One such element of concern is the coupling of lateral and torsional modes as a result of the eccentricity between Centre of Mass (CM) and Centre of Rigidity (CR). This issue is generally found in asymmetric buildings, as the mass concentration and stiffness concentration could be found at distinct points because of the asymmetry the structure shows in its plan. As a result of this eccentricity, torsional vibration is additionally found in the response where otherwise purely translational vibration occurs. This is due to the non-concurrent lines of action of inertia force and the resistive force, as the former acts through the CM while the latter acts through the CR; causing a time varying twisting moment.

Mass eccentricity is when there is an asymmetric distribution of masses over the floor slabs, even while the structure is symmetric with respect to stiffness and strength. This can happen due to mass concentration in certain floor levels by the presence of machineries, water tanks etc. Such a situation can cause the displacement of CM from the geometric centre resulting in mass asymmetry for a building which is in fact symmetric with respect to stiffness and strength. 
Studies and analysis on the torsional behaviour of buildings under seismic loads due to asymmetry in plan has been the focus of many intense investigations over the past three decades. Many literature were published over the decades on asymmetric behaviour but most studies were confined to buildings having stiffness eccentricity. Studies on mass eccentricity, being a very specific topic, is very limited and a review of literature on the topic is non-existent as to the author's knowledge. This paper, thus, aims to provide a comprehensive review on the studies done on buildings having asymmetry in mass and thereafter arrive at a conclusion about their behaviour.

\section{Code Specification}

In order to classify building structures based on their geometry, different seismic codes have come up with different criterions. These indices decide whether a structure need to be designed as irregular when a particular code is considered for the design. The limits on mass eccentricity specified by various codes are given in Table 1 . It should be noted that in case of plan asymmetry, the codal provisions across the world doesn't differ the criterion of mass eccentricity from stiffness eccentricity; as the presence of any of them is enough to cause torsion.

Table 1: Mass eccentricity limits specified by various building codes

\begin{tabular}{|l|l|ll|}
\hline Code & Torsional Irregularity & $\begin{array}{l}\text { Vertical mass } \\
\text { irregularity }\end{array}$ & m \\
\hline IS 1893:2016 & $\mathrm{d}_{\max } \leq 1.2 \mathrm{~d}_{\mathrm{avg}}$ & $\mathrm{M}_{\mathrm{i}}<2 \mathrm{M}_{\mathrm{a}}$ & \\
\hline EC8 2004 & $\begin{array}{l}\mathrm{r}_{\mathrm{x}}>3.33 \mathrm{e}_{\mathrm{ox}} \\
\mathrm{r}_{\mathrm{y}}>3.33 \mathrm{e}_{\mathrm{oy}} \\
\mathrm{r}_{\mathrm{x}} \text { and } \mathrm{r}_{\mathrm{y}}>\mathrm{d}_{\mathrm{s}},\end{array}$ & $\begin{array}{l}\text { Should } \\
\text { abruptly }\end{array}$ & reduce \\
\hline UBC 97 & $\mathrm{d}_{\max } \leq 1.2 \mathrm{~d}_{\mathrm{avg}}$ & $\mathrm{M}_{\mathrm{i}}<1.5 \mathrm{M}_{\mathrm{a}}$ & \\
\hline NBCC 2005 & $\mathrm{d}_{\max } \leq 1.7 \mathrm{~d}_{\mathrm{avg}}$ & $\mathrm{M}_{\mathrm{i}}<1.5 \mathrm{M}_{\mathrm{a}}$ & \\
\hline IBC 2003 & - & $\mathrm{M}_{\mathrm{i}}<1.5 \mathrm{M}_{\mathrm{a}}$ & \\
\hline TEC 2007 & $\mathrm{d}_{\max } \leq 1.2 \mathrm{~d}_{\mathrm{avg}}$ & - \\
\hline ASCE 7.05 & $\mathrm{d}_{\max } \leq 1.2 \mathrm{~d}_{\mathrm{avg}}$ & $\mathrm{M}_{\mathrm{i}}<1.5 \mathrm{M}_{\mathrm{a}}$ & \\
\hline
\end{tabular}

As a result of eccentricity in plan, torsional forces are induced in the structure about the vertical axis, resulting in increased shear forces in the lateral force resisting elements. Provisions are made in building codes to consider this effect. Seismic codes specify that lateral forces induced due to seismic loads need to be applied at a distance equal to a design eccentricity whereby the CM is displaced from its reference position. The design eccentricity in any floor $\mathrm{i}$ is given by

$$
\begin{aligned}
& \mathrm{e}_{\mathrm{di}}=\alpha \mathrm{e}_{\mathrm{i}}+\beta \mathrm{D} \\
& \mathrm{e}_{\mathrm{di}}=\delta \mathrm{e}_{\mathrm{i}}-\beta \mathrm{D}
\end{aligned}
$$

where $\mathrm{D}$ is the dimension of the floor plan normal to the direction of the seismic waves; $\mathrm{e}_{\mathrm{i}}$ the static eccentricity of floor $\mathrm{i}$ (distance between $\mathrm{CM}$ and $\mathrm{CR}$ ). The value of $\mathrm{e}_{\mathrm{di}}$ for which greater force is observed is taken for each element. $\alpha, \beta$ and $\delta$ are constants which varies across different codes, the values of some of which are given in Table 2. Factor $\alpha$ is the dynamic amplification 
factor considered to include the dynamic effects of torsional response while doing equivalent lateral force method. $\delta$ is meant for the negative shear as a result of torsion which needs to be reduced while designing the elements on 'stiff' side. The latter part of the equation given by $\beta \mathrm{D}$ is termed as accidental eccentricity, compensates for the minimum eccentricity requirements and is defined as a fraction of the plan dimension.

Table 2: Constant values for torsion in various building codes

\begin{tabular}{|c|c|c|c|}
\hline Code & $\alpha$ & $\beta$ & $\delta$ \\
\hline IS 1893 & 1.5 & 0.05 & 1 \\
\hline NBCC 2005 & 1.5 & 0.1 & 0.5 \\
\hline UBC 97 & 1.0 & $\begin{array}{l}\operatorname{Ax}(0.05 \mathrm{~b}) \\
\quad A x=\left(\frac{\delta \max }{1.2 \delta a v g}\right)^{2}\end{array}$ & 1.0 \\
\hline NEHRP 1997 & $A x$ & $0.05 \mathrm{Ax}$ & Ax \\
\hline NZ standard & 1 & 0.1 & 1 \\
\hline Mexico Code & 1.5 & 0.1 & 0.5 \\
\hline
\end{tabular}

\section{Mass Eccentricity in Plan}

Asymmetry of mass is observed when the CM of a particular storey or floor of a building gets displaced from its geometric centre. This is illustrated in Fig. 1. The eccentricity thus formed could be either uniaxial or biaxial depending on the intensity of additional mass implied upon the floor. Building models used for most of the studies were that of simple geometries with some sort of lumped mass which could cause the desired mass eccentricity. Initial studies on the topic were limited to single storied buildings idealized as shear beam models. It was only later that multi storied buildings came into study. Plastic hinge idealized structures were then found to exhibit closeness to real time behaviour as compared to that of shear beam models. Inelastic analyses were mostly carried out.

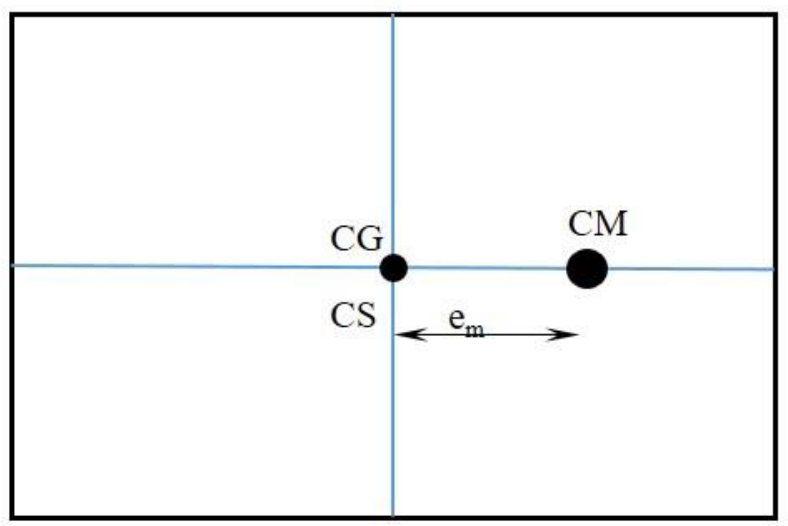

Figure 1: Mass Eccentricity in Plan 


\section{a) Single Storied Buildings}

Ratio of uncoupled torsional frequency to the uncoupled lateral frequency is an important parameter while determining the torsional response of an eccentric building. Known as the uncoupled frequency ratio, study on its effect on a single storied mass eccentric building was carried out by Tso and Dempsey [1] in as early as 1980. When the ratio approaches unity, the torsional response was found to peak for small eccentric systems and is substantially reduced for about $25 \%$ of difference from unity whereas large eccentric systems are not much sensitive to this ratio. They also compared the edge displacements of both symmetric and eccentric systems having various aspect ratios using response spectrum method and pointed out that eccentric effects are more significant on systems having lesser aspect ratio.

Since the previous study was on simplified elastic model, Tso along with Sadek [2] investigated the inelastic response of a single storied building under torsion due to seismic loads. The new findings contradicted their observation on peak response when the uncoupled frequency ratio reaches unity. They investigated the ductility response of a bilinear system under varying eccentricity and observed that for a definite torsional stiffness, ductility demand is seen to be increasing with eccentricity. Analysis using Clough's stiffness degradation model showed similar results as well.

Study on elastic behaviour of mass eccentric buildings under time history loads and response spectrum method was carried out by Chandler and Hutchinson [3] by taking frequency ratio and eccentricity values were taken as the prime parameters. Torsional response quantities such as dynamic shear force, torque and storey torque were found to be dependent on the variation of these parameters and were not adequately represented in building codes. They validated the results of time history analyses with the existing response spectrum methods and proposed improvements on torsion provisions in building codes.

Tso and Ying [6] differentiated resistance eccentricity as an uneven distribution in resistance of buildings and observed that elements away from this Centre of Rigidity are more critical to torsional effects and has higher ductility demands. The research was based on stiffness eccentric single storied model. Study on building codes has shown that better strength distribution comes in cases having no resistance eccentricity. This result was contradicted by Gomez et al. who studied resistance eccentricity in mass eccentric buildings and proposed better behaviour on buildings having resistance eccentricity equal to mass eccentricity.

Goel and Chopra [3] studied the elastic and inelastic behaviour of an idealized single storied asymmetric building under seismic excitation and suggested that period dependency of torsional response is comparatively less in inelastic systems. A simple input and El-Centro excitation were used for the study and confirming the proposal by [1], they suggested that the torsional deformation is maximum when the frequency ratio is close to unity. Acceleration and Velocity sensitive regions of response spectra were seen to affect the peak deformation of resisting elements in cases of asymmetry and strength symmetric buildings ( 0 resistance eccentricity) appeared to show symmetric behaviour under increasing inelastic action. 
Wong and Tso [4] used the response spectrum method to study the seismic response of single mass torsionally unbalanced structural systems. By modelling structures with and without accidental eccentricity, they considered the impact of it on elastic spectrum analysis. Additional ductility demand was observed on the stiff side elements in cases where accidental torsion was neglected. A general observation on the dependency of edge displacements of a structure to its torsional stiffness was made for elastic behaviour, while the same was observed to be negligible in the inelastic behaviour.

Noticing that the studies so far has shown contradictory results about the inelastic response of asymmetric buildings with respect to uncoupled frequency ratio, Annigeri et al [5] tried to clarify the inconsistency surrounding the topic. This contrast in results could be attributed to the use of different models, time period, strength distributions and definition of UFR in the studies. Depending on the position of Centre of Stiffness and Centre of Mass, 3 different UFR were defined in this study and analyzes were carried out for 9 eccentric systems considered for the study. The results showed that the response doesn't actually peak when the frequency ratio is unity and is not critical which contradicts many of the previous study. Also the ductility demand on stiff side elements was found to be decreasing with increasing UFR while the flexible side elements displayed a proportional relationship in ductility demand with frequency ratio.

Hao [6] used multidirectional time history loads to study biaxial eccentricity in mass eccentric buildings. He considered a one storied building having a large span of $100 \mathrm{~m}$ to emphasize the coherency loss effects and compared base shear, torque and column shear to varying eccentricity in both uniaxial and biaxial directions. One way eccentricity has decreasing effect on base shear while two way eccentricity improves it, the effect of latter being insignificant when compared to the reduction due to non-uniform excitation. Similar is the case with torque, where torsionally flexible and intermediate structures correspond more to non uniform excitation than eccentricity, while stiff buildings respond to eccentricity more.

Tso and Smith [7] proposed the use of D-type (Yield Displacement Constant type) elements over K-type (Stiffness Constant type) elements to mitigate torsional effects caused by structural asymmetry as they do not change the yield displacement of the systems designed under torsional provisions and are capable of limiting the additional ductility demands. A single storied mass eccentric building was adopted for the study and ductility demands of both flexible and rigid side elements of the building was compared. Even though no severe increase in ductility demand was observed for torsionally unbalanced system in their both sides, torsionally flexible systems displayed criticial ductility demand for their stiff edge when K-type elements were used.

Stefano and Pintucchi [9] developed a refined numerical model of one-storey plan asymmetric building structure, which unlike other models considered till then, can take into account presence of vertical forces due both gravity loads and vertical input ground motions as well as effects of inelastic interaction between axial force and bi-directional horizontal forces. Analysis using this new model suggested that interaction phenomena between these forces considered is in fact significant. This observation can be attributed to the increased ductility demand in resisting elements. 
Extensive literature and conclusions on elastic behaviour of asymmetric buildings had been carried out over the years but the nonlinear behaviour has been an area of unorganized and contradictory results. Observing this, Lucchini et al [15] went on to investigate and compare the nonlinear behaviour of single storied mass eccentric buildings under uniaxial excitation. The study showed that there is infact a change in response of the system when the behaviour moves from linear to nonlinear range. Another interesting trend observed from the study was that nonlinearity gets amplified with increasing earthquake intensity and thus the maximum displacement demand in the different resisting elements tends to be reached with the same deformed configuration of the system. The authors proposed the need of additional studies with multistoried and more complex systems under biaxial excitations.

\section{b) Multi Storied Buildings}

Hejal and Chopra [1] studied the dependence of the response of torsionally coupled multi storied buildings under various parameters, the plan of which is shown in figure. They considered moment resisting frames under idealized response spectra curves and observed the inter dependency of response quantities with higher modes and the parameters considered for the study such as eccentricity ratio, frequency ratio, stiffness ratio, damping ratio and the fundamental period of the torsionally uncoupled multi-storey system. While in a companion paper [2] they observed that lateral-torsion coupling arising due to asymmetry in buildings affects the response spectra to varying degrees depending on eccentricity ratio, torsional stiffness and the different control regions on the spectrum. But the coupling effect is seen to be insignificant on the height wise variation of forces. They were able to idealize the 5-storied building considered into a single storied building having similar coupling response.

A comparison between theoretical and experimental studies on mass eccentric multi storied structures were conducted by Maheri et al. [3] A series of test models having varying frequency ratio in symmetric asymmetric configurations were tested using a shake table apparatus under various earthquake inputs. Experimental results suggested that the theory has overestimated the contribution of first lateral mode and has underestimated the significance of torsional mode, while determining the torsional response, especially in buildings having low uncoupled frequency ratio.

An improvement over the standard multi model analysis was propsosed by Ghersi et al [4] who developed a design procedure involving the application of the multi modal analysis twice using CQC combination rule. Multi storied mass eccentric buildings having varying values of torsional stiffness and eccentricity was used for the study. It was seen that the proposed design is capable of reducing the rotational ductility demands of upper storey beams where the response had been doubled due torsional unbalancing

Samali et.al [5] studied the effect of mass eccentric buildings with base isolation using rubber bearings. They investigated the effect of torsion using a shake table apparatus. They concluded experimentally that use of elastomeric rubber bearings has a significant effect in reducing the torsional deformation, model relative displacement and acceleration in a mass eccentric superstructure. The results were validated with that of finite element analysis. 
To determine the effectiveness of modal pushover analysis (MPA) on the seismic response of unsymmetric buildings, Chopra and Goel [6] carried out studies on multistoried mass eccentric buildings. By varying the ratio between polar moment of inertia and the mass, 3 types of unsymmetric models were generated, namely; (a) torsionally stiff (b) torsionally flexible, and (c) torsionally similarly stiff. It was observed that for the first two systems, MPA can be considered as an appropriate method of non-linear seismic design procedure as it could predict accurate seismic demand to the same degree as for the symmetric counterpart. But for the torsionally stiff system, stronger coupling of elastic modes and under estimation of of roof displacement by CQC rule caused the MPA procedure to be fairly inaccurate as to be used for estimating seismic demand.

A suggestion put forth by Chambers and Kelly [7] stated that the only valid method in which irregular buildings can be analyzed is through the application of non-linear dynamic procedures. The basis of their statement is that the NDP methods considers no simplification or assumptions and fully takes into consideration both the dynamic and non-linear aspects of building design. While the other methods were developed considering semi-empirical relations on a narrow set of models considered, NDP is not so and takes into account effects such as ductility, P-Delta, dynamic magnification etc. Case studies of some existing irregular buildings were carried out by the authors to validate their proposal and observed that NDP is in fact a superior method of analysis over conventional methods.

Vial et al [8] investigated multi storied mass eccentric building models incorporated with frictional dampers. Both analytical and experimental studies were done and it was observed that the dampers can substantially decrease the response due to torsion in the models considered which suggested a general decreasing trend of response in mass eccentric buildings. An empirical centre of balance (ECB) was defined equidistant to both the edges of the buildings, such that mean square values of response on both the edges will be similar. Experimental results proved that when the dampers were optimally placed, both flexible and stiff side elements demanded similar displacement response

Dogan et.al [9] studied about the earthquake of cantilever projection buildings in Turkey. They studied about the various overhang systems and their seismic behaviour and arrived at the conclusion that overhangs form eccentricity on buildings and the eccentricities as the overhang length increases. They didn't propose any solution but suggested that overhangs, if possible, should be not be used at all as they make the load calculation more complex and decrease the earthquake strength of the structure.

During the inelastic phase, there occurs a change in stiffness with each step in buildings, causing an inconsistency in the Centre of Rigidity and thus a step by step variation of static eccentricity, Tabatabei and Saffari [10] proposed a simplified procedure of pushover (nonlinear static) analysis with varying eccentricity based on modal response of single-storey scheme. This modified procedure was found to be providing accurate estimation of demands in asymmetric buildings through validation with adaptive model combination estimate procedure. Study results indicate that, in the inelastic range, the predominantly translational and torsional periods owing to plastic deformations are too variable. Hence, the conventional pushover analysis is unable to capture the 
inelastic displacements at the edges, particularly, in torsionally flexible behavior. This can only be achieved using updated static eccentricity at each nonlinear static procedure step.

Bagheri et.al [11] compared the three types of analyses; namely static, response spectrum and time history on irregular multi storied structures and proposed the efficiency of time history method as compared to other types of analyses. They observed that that displacement values observed from static methods are larger and thus yields uneconomical design.

Coupling between lateral and torsional modes under seismic loads is the primary effect caused due to structural asymmetry. Yiu et al [12], from their studies on multistoried mass eccentric buildings, proposed a practical method for assessing this lateral-torsional coupling. The method involves decoupling the lateral and torsional modes from the coupled system using a transformation technique. From this, an equivalent single mass eccentric system was developed and additional lateral translations due to building asymmetry can be found out in terms of eccentricity and uncoupled period ratios. Lateral-torsional coupling was found to have a proportional relationship with these two parameters. The results of the proposed method were then validated using on two example 30-storied buildings.

Observing that a qualitative index that can accurately depict the variation in response parameters due to building asymmetry is lacking even after extensive research on the topic for decades, Stathi et al [13] derived and put forth Ratio of Torsion (ROT), an efficient index aimed at evaluating the torsional response of mass irregular buildings. To validate the reliability of the proposed index, nonlinear dynamic analyses were conducted on single as well as multi storied regular and torsionally stiff double eccentric mass irregular buildings. The proposed ROT index was found to be predicting accurately shear and torque response of the test buildings considered. Furthermore, ROT was observed to be following the existing conclusions in unsymmetric building literature, such as increased response at flexible edges and decreased response at stiff edges. For the considered building as shown in fig. ROT is given by

$$
R O T=\frac{\left|V_{3 x y}\right|+\left|V_{4 x y}\right|}{\left|V_{E y}\right|}
$$

The numerator represents the sum of the absolute values of the additional torsion induced shear forces and the denominator represents the base shear imposed by the seismic excitation.

Observing that the seismic behaviour of asymmetric braced frame type structures have not been given considerable attention in the literature, McCrum and Broderick [14] went on to investigate them. The model considered was a 3 storied single bay building having mass eccentricity in the order of $15 \%$. Nonlinear time history analysis was conducted to determine and compare the additional ductility demand, interstorey drift and floor rotations to that of symmetric counterpart. A new proportional relationship between the normalized ductility demand and slenderness ratio was observed as a result of the study. Also considerable amplification of the considered parameters was found at high acceleration values for torsionally flexible eccentric building.

Tehrani and Mellati [15] analyzed 10 storied one way mass eccentric buildings using modified consecutive modal pushover (MCMP) procedure. Both torsionally flexible and torsionally stiff 
sides were used for determining floor displacements, drift ratio and plastic hinge rotations. MCMP procedure was found out to have an upper hand over Modal Pushover analysis (MPA). Differences in bidirectional and unidirectional ground motions were observed for storey displacements with respect to the CM. Both stiff and flexible sides undergo larger displacements in Torsionally stiff as well as torsionally flexible systems in bidirectional loading. But for unidirectional loading; (1) only stiff side has larger displacement compared to CM in flexible systems; and (2) only flexible side has larger displacement compared to CM in stiff systems. The results are summarized in table.

Table 3: Comparison of stiff and flexible systems under various types of loading

\begin{tabular}{|l|l|l|}
\hline & $\begin{array}{l}\text { Bidirectional } \\
\text { loading }\end{array}$ & $\begin{array}{l}\text { Unidirectional } \\
\text { loading }\end{array}$ \\
\hline $\begin{array}{l}\text { Torsionally } \\
\text { stiff system }\end{array}$ & SS $>$ CM, & FS $>$ CM $>$ SS \\
\hline $\begin{array}{l}\text { Torsionally } \\
\text { flexible } \\
\text { system }\end{array}$ & FS $>$ CM, & SS $>$ CM $>$ FS \\
\hline
\end{tabular}

Feizi and Saadeghvaziri [16] attempted to optimize the eccentricity and frequency ratio such that maximum reduction in translational vibration may be achieved. Kanai-Tajimi power spectral density function (Fig. 2) is used to model the ground motion. Studies conducted on single and multi-storied eccentric buildings indicated that upto $50 \%$ of reduction in performance index and top storey displacement can be achieved. A case study was done which validated the results of the study to a comparable range. Unlike the other researches on eccentric buildings so far, this study actually suggests eccentricity as a method of vibration control. The authors proposed the application of this approach in replacing existing control equipment such as the tuned mass dampers, which occupies large space in the structure.

A study on the variance of collapse capacity in low-rise RC buildings due to the presence of asymmetry was carried out by Badri et al [17] . Mass eccentricity to the scale of 10 and 20\% was considered for inducing asymmetry and the parameters used were plastic rotation capacity, postcapping rotation capacity and cyclic energy-dissipation capacity. First-order-second-moment method is used to assess the variance of collapse capacity. Independent of building asymmetry, plastic rotation capacity was found to be contributing the most to the variance. Record-to-record variability has more influence on the response variability compared to variability in modeling parameters, and this contribution further increases with increase in eccentricity.

Wiliams and Tripathy [18] analyzed a 15 storey mass asymmetric building for linear and nonlinear behaviour. Intensity of mass and the magnitude of asymmetry were found to be proportionally related to top storey displacement, base shear and storey drift, with the former denominating. 
Biaxial asymmetry was seen to induce more torsion compared to uniaxial asymmetry. They also observed the effect of shear walls in improved behaviour of mass irregular buildings.

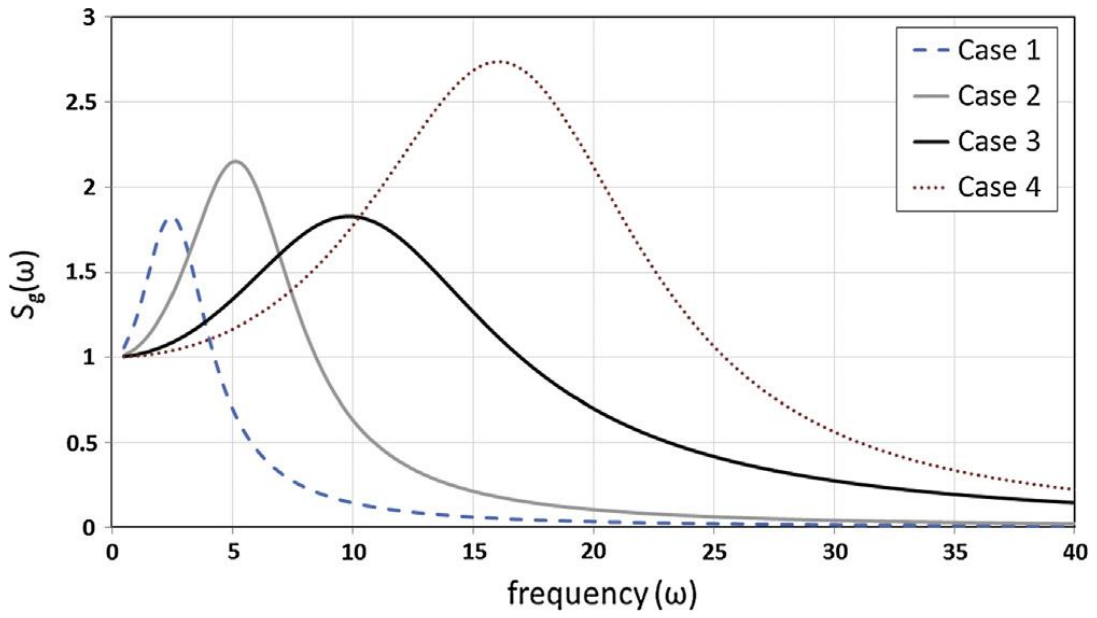

Figure 2: Kanai-Tajimi power spectral density

Nezamisavojbolaghi and Hosseini [19] considered the behaviour of special hospital equipment as rigid blocks causing mass eccentricity. They considered the stability of ventilators during seismic loads. By varying the eccentricity and earthquake data, a total of above 6000 analysis cases were done using fourth order Runge-Kutta-Nistrom technique. He observed that even with increase in only $1 \%$ of $g$ in the PGA of the record, the mode of behavior changes from rocking to overturning. Based on these results it can be said that the criteria, being used currently for seismic evaluation of equipment, needs to be modified.

\section{Vertical Mass Eccentricity}

Mass eccentricity in elevation is a result of irregularity of mass distribution along height. As a result the CM will get displaced from the vertical centroid axis.

Tremblay and Poncet [20] studied eight storey buildings having a concentric braced steel frame. Different configurations of setback was used in order to vary the dimensions and seismic weight of the building models along height. Both equivalent static and response spectrum methods of analysis were employed here. They observed that except for buildings with mass discontinuity at mid height, irregular structures designed with the dynamic method behaved similar to or better than the regular structure. For immediate occupancy, mass irregularity has limited effects on elastic building response. If needed, these effects can be reduced, and perhaps eliminated, by using a dynamic analysis method.

Georgoussis [21] considered the dynamic response of eccentric buildings with a setback. He proposed a method of calculating various seismic parameters by having an equivalent single story eccentric system. The accuracy of the parameters obtained by this study; namely the frequency, base shear and torque are validated using accurate stiffness analysis and acceptable limits of engineering practice. The method may be found useful to practicing engineers at the early stages 
of a structural design, where the decision about the structural layout has to be taken prior to full dynamic analysis

Aydin [22] studied two dimensional multi storied structures idealized as shear and frame buildings by static as well as time history method. By varying the mass of any particular floor, he obtained mass eccentricity in elevation. Studies were conducted on 5, 10 and 20 storied models. The author concluded that the shear in stories below the asymmetric floor is influenced by mass eccentricity and that the static method always overestimates the seismic response in comparison to time history analysis.

\section{Accidental Eccentricity}

Studies specific to accidental torsion in buildings began as early as from 1992 when Chopra, being a pioneer researcher in the field of building asymmetry, evaluated the UBC building code provisions for three nominally-symmetric plan buildings, along with fellow researcher De La Lera [23]-[25]. They presented a procedure to determine and compare the actual time varying member forces to that of design member forces so as to verify the conservativeness of accidental torsion. They concluded the efficiency of UBC to represent accidental torsion in the models considered and suggested that the eccentricity provision may be neglected while designing as the additional ductility demand is small.

Extending their study on the three nominally symmetric real time buildings(Figure ) Llera and Chopra (1994) checked the adequacy of accidental torsion in building codes. They concluded the sufficiency of code provisions for the cases considered. In cases of buildings with a larger torsional vibration period than that of translation, inclusion of accidental eccentricity was found to be effective. Such is the case with buildings having masonry wall or partitions. Dynamic accidental eccentricity, according to the studies was given as

$$
\operatorname{exj}(t)=\frac{\operatorname{Tj}(t)}{\operatorname{Vyj}(t)} \quad \operatorname{eyj}(t)=\frac{T j(t)}{\operatorname{Vxj}(t)}
$$

Llera and Chopra [24] on further studies proposed a new method of determination of accidental torsion in buildings which had in many aspects, an upper hand over the code specific methods such as taking into consideration all the actual factors which affect the accidental torsion. The new method involved amplification of the resisting plane forces from a factor obtained by calculations using frequency ratio and edge displacements.

Ramadan et al. [26] studied the efficacy of code provision of 5\% accidental torsion by modelling many number of multi storied structures in OpenSees and analyzing them using ground motion data. Monte Carlo Simulation technique was used for about 300 accidental eccentricity samples from assumed Probability Density Functions. They observed that the accidental eccentricity at each floor is dependent on the number of stories above it. They concluded and proposed that building codes have overestimated the $5 \%$ accidental eccentricity (10\% in some other) for floors having higher number of stories above.

Studying the code accidental torsion provisions Chandler et al. [27] presented the difference in flexible and stiff side elements through inelastic analysis. They investigated the effects of 
accidental eccentricity in the distribution of element design strength through code procedures. It was observed that torsionally unbalanced system has a lesser ductility demand than that of balanced system. Variation is flexible and stiff sides were found to be dependent on the amount of stiffness as well as time period of the structure.

Stathopoulos and Anagnastopoulos [28], who have done a considerable amount of work on asymmetry in buildings, extended their research on the effect of accidental eccentricity. Analysis results of a simplified one storey shear beam model and that of 1,3 and 5 storied frame type models were considered under various conditions of design eccentricity, accidental design eccentricity and accidental mass eccentricity. Results on ductility demand obtained from the shear beam type was seen to contradict that of the more realistic frame type models. Also observed was the futility of accidental eccentricity in substantially reducing the response of the eccentric frame type models. Thus the study concluded that the code provision of accidental eccentricity is mainly suited to either shear beam models or frame type buildings of symmetric configuration of mass and stiffness.

Considering the collapse capacity of buildings as a parameter, DeBock et al. [29] studied the influence of code accidental eccentricity provision on 230 building models having varied geometry, loading pattern and eccentricity. They observed that the inclusion of accidental torsion substantially influences the collapse capacity of buildings that are either torsionally flexible or significantly asymmetric. Buildings that are torsionally stiff and regular are generally unaffected by inclusion of accidental eccentricity. They concluded that buildings which are neither torsionally flexible nor asymmetric need not be designed with accidental eccentricity.

While the provision of accidental torsion accounts for the uncertainity in design factors which may cause torsion, the implementation of it shall make the building analyses more complex and can significantly increase the work load. Also the provision was introduced in various codes by analyzing the observations made on simplified one storey elastic models which totally neglects the more realistic inelastic mulstistorey builidngs. Considering these limitations and influenced by the studies of DeBock et al. [29], Anagnostopoulos et al. [30] extended their previous study [31] to find out the efficacy of accidental torsion in Eurocode 8 using multistoried eccentric braced steel buildings. Models were designed considering various factors which are summarized in Table 4. It was observed that for torsionally stiff systems, the code specification of accidental eccentricity is irrelevant and is better removed or a simpler provision should be made. And as for torsionally flexible systems, accidental eccentricity was found to be somewhat effective in reducing the ductility demands.

Table 3: Design considerations by [30]

\begin{tabular}{|l|l|}
\hline Number of Stories & 3 \\
& 5 \\
\hline \multirow{2}{*}{ Torsional Rigidity } & Torsionally Stiff \\
& Torsionally Flexible \\
\hline \multirow{3}{*}{ Mass eccentricity } & $\mathrm{e}_{\mathrm{m}}=0.0$ \\
& $\mathrm{e}_{\mathrm{m}}=0.10$ \\
& $\mathrm{e}_{\mathrm{m}}=0.20$ \\
\hline
\end{tabular}




\begin{tabular}{|l|l|}
\hline $\begin{array}{l}\text { Accidental mass } \\
\text { eccentricity (AME) }\end{array}$ & $\mathrm{AME}=0$ \\
$\mathrm{AME}= \pm 0.5$ \\
\hline $\begin{array}{l}\text { Accidental design } \\
\text { eccentricity (ADE) }\end{array}$ & $\mathrm{ADE}=0$ \\
$\mathrm{AME}= \pm 0.5$ \\
\hline
\end{tabular}

Lin et al. [32] applied discrepancy curves to understand the suitability of amplification factor ' $A_{x}$ ' for accidental torsion as specified by certain buildings codes. The results implied the necessity of Ax only for low rise buildings if the displacements of Centre of Mass and Flexible Sides need to be calculated. As for the displacements of Stiff Side, the amplification factor was found suitable for all types of rise and torsion in buildings except for torsionally flexible or torsionally similarly stiff low rise and medium rise buildings. Such cases was proposed with only a negative value of accidental eccentricity and a modified amplification factor.

To account for the effect of torsional ground motion in determining the response of a building, an alternative definition of accidental eccentricity was proposed by Basu et al. [33]. For the study, both torsionally stiff and flexible single storied buildings were considered and the results were assumed to be applicable to multi storied buildings as well by verifying the validity of results. The method involved applying a torsional ground motion, obtained as a result of multiplying the translational ground motion with a factor, which is obtained from the proposed accidental eccentricity. The eccentricity required is when the actual torsional amplification is achieved as determined by actual torsional ground motion.

\section{Conclusion}

Irregularity in mass and stiffness distribution can cause torsion under seismic loads in a building system. More than half of the building failures due to earthquakes were attributable to this asymmetry. There has been, over the years, many attempts to classify and analyse the buildings having mass irregularity and arrive at observations and results. Building codes have provisions that defined design eccentricity and calculates the largest possible lateral force for resisting elements.

Asymmetry divides the structure having 'flexible' and 'rigid' sides. It is observed that the flexible sides demand more ductility to withstand seismic loads as compared to the rigid side. Also the displacements tend to increase in the flexible sides. Thus necessitating the need to strengthen the flexible side. Asymmetry also redistribute the shear force demands in the stories below the floors having eccentricity. Code provisions of equivalent lateral force method to analyse eccentric buildings are found to be overestimating the shear force demands as compared to time history analysis.

Some authors were able to come up with better techniques and methods to reduce the effect due to mass asymmetry. Friction dampers were found to have a better resistance to irregularity. Base isolation using laminated rubber bearings has a significant effect on the torsional response of mass eccentric buildings. 


\section{References}

[1] R. Hejal and A. K. Chopra, "Earthquake Response of Torsionally Coupled, Frame Buildings,” J. Struct. Eng., vol. 115, no. 4, pp. 834-851, 1989, doi: 10.1061/(ASCE)07339445(1989)115:4(834).

[2] R. Hejal and A. K. Chopra, "Lateral-Torsional Coupling in Earthquake Response of Frame Buildings," J. Struct. Eng., vol. 115, no. 4, pp. 852-867, 1989, doi: 10.1061/(ASCE)0733-9445(1989)115:4(852).

[3] M. R. Maheri, A. M. Chandler, and R. H. Bassett, "Coupled lateral-torsional behaviour of frame structures under earthquake loading," Earthq. Eng. Struct. Dyn., vol. 20, no. 1, pp. 61-85, 1991, doi: 10.1002/eqe.4290200106.

[4] A. Ghersi, E. Marino, and P. P. Rossi, "Inelastic response of multi-storey asymmetric buildings," Proc. 12th World Conf. Earthq. Eng. Auckland, New Zeal., pp. 1-8, 2000.

[5] B. Samali, Y. M. Wu, and J. Li, "Shake table tests on a mass eccentric model with base isolation," Earthq. Eng. Struct. Dyn., vol. 32, no. 9, pp. 1353-1372, 2003, doi: 10.1002/eqe.277.

[6] A. K. Chopra and R. K. Goel, "A modal pushover analysis procedure to estimate seismic demands for unsymmetric-plan buildings," Earthq. Eng. Struct. Dyn., vol. 33, no. 8, pp. 903-927, 2004, doi: 10.1002/eqe.380.

[7] J. Chambers and T. Kelly, "Nonlinear Dynamic Analysis - The Ony Option for Irregular Structures," 13th World Conf. Earthq. Eng., no. 1389, 2004.

[8] I. J. Vial, J. C. D. la Llera, J. L. Almazan, and V. Ceballos, "Torsional balance of planasymmetric structures with frictional dampers: Experimental resu," Earthq. Eng. Struct. Dyn., vol. 35, no. September, pp. 1875-1898, 2006, doi: 10.1002/eqe.

[9] M. Dogan, E. Unluoglu, and H. Ozbasaran, "Earthquake failures of cantilever projections buildings," Eng. Fail. Anal., vol. 14, no. 8 SPEC. ISS., pp. 1458-1465, 2007, doi: 10.1016/j.engfailanal.2007.01.008.

[10] R. Tabatabaei and H. Saffari, "Evaluation of the Torsional Response of Multistory Buildings Using Equivalent Static Eccentricity," J. Struct. Eng., vol. 137, no. August, pp. 862-868, 2011, doi: 10.1061/(ASCE)ST.1943-541X.0000324.

[11] B. Bagheri, E. S. Firoozabad, and M. Yahyaei, "Comparative study of the static and dynamic analysis of multi-storey irregular building," World Acad. Sci. Eng. Technol., vol. 6, no. 11, pp. 1847-1851, 2012.

[12] C. Yiu, C. Chan, M. Huang, and G. Li, "Evaluation of lateral-torsional coupling in earthquake response of asymmetric multistory buildings," Struct. Des. Tall Spec. Build., vol. 24, no. July 2014, pp. 421-439, 2014, doi: 10.1002/tal.1102.

[13] C. G. Stathi, N. P. Bakas, N. D. Lagaros, and M. Papadrakakis, "Ratio of Torsion (ROT): An index for assessing the global induced torsion in plan irregular buildings," Earthq. Struct., vol. 9, no. 1, pp. 145-171, 2015, doi: 10.12989/eas.2015.9.1.145. 
[14] D. P. McCrum and B. M. Broderick, "Seismic assessment of a steel braced plan mass symmetric/asymmetric building structure," J. Constr. Steel Res., vol. 101, pp. 133-142, 2014, doi: 10.1016/j.jcsr.2014.05.010.

[15] M. H. Tehrani, A. Mellati, M. Fallahian, and F. Khoshnoudian, "Evaluation of Different Lateral Load Patterns in Estimating Seismic Demands of 3D Mass Eccentric Mid-rise Building Evaluation of Different Lateral Load Patterns in Estimating Seismic Demands of 3D Mass Eccentric Mid-rise Building," Int. J. Struct. Anal. Des., no. February 2016, 2013.

[16] B. Feizi and M. Ala Saadeghvaziri, "Optimal design of eccentricity for seismic applications," Eng. Struct., vol. 59, pp. 646-653, 2014, doi:

10.1016/j.engstruct.2013.11.023.

[17] R. K. Badri, M. Nekooei, and A. S. Moghadam, "The Variance of Collapse Capacity of Symmetric and Asymmetric Low-Rise RC-SMF Buildings," J. Earthq. Eng., vol. 19, no. 8, pp. 1181-1196, 2015, doi: 10.1080/13632469.2015.1049387.

[18] R. K. Tripathi, "Study of Effect of Eccentricity on the Linear andNonlinear Behaviour of RCC Irregular Buildings,” Int. J. Eng. Res., vol. 5, no. 4, pp. 275-278, 2016.

[19] K. Nezamisavojbolaghi and M. Hosseini, "Behavior of Special Hospital Equipments as Rigid Block with Mass Eccentricity Subjected to Horizontal Component of Ground Motion," in Procedia Engineering, 2017, vol. 199, pp. 753-758, doi: 10.1016/j.proeng.2017.09.040.

[20] R. Tremblay and L. Poncet, "Seismic Performance of Concentrically Braced Steel Frames in Multistory Buildings with Mass Irregularity," J. Struct. Eng., vol. 131, no. 9, pp. 13631375, 2005, doi: 10.1061/(ASCE)0733-9445(2005)131:9(1363).

[21] G. Georgoussis, "Simplified dynamic analysis of eccentric buildings with a setback. 1: the effect of mass irregularity," Struct. Des. Tall Spec. Build., vol. 20, no. 8, pp. 911-927, 2009, doi: 10.1002/tal.567.

[22] K. Aydin, "Evaluation of Turkish seismic code for mass irregular buildings," Indian J. Eng. Mater. Sci., vol. 14, no. 3, pp. 220-234, 2007.

[23] J. C. De la Llera and A. K. Chopra, "Using accidental eccentricity in code specified static and dynamic analyses of buildings," Earthq. Eng. Struct. Dyn., vol. 23, no. 9, pp. 947967, 1994, doi: 10.1002/eqe.4290230903.

[24] J. C. De la Llera and A. K. Chopra, "Estimation of Accidental Torsion Effects for Seismic Design of Buildings," J. Struct. Eng., vol. 121, no. 1, pp. 102-114, 1995, doi: 10.1061/(ASCE)0733-9445(1995)121:1(102).

[25] J. C. De la Llera and A. K. Chopra, "Evaluation of Code-Accidental Torsion Provisions Using Earthquake Records from three nominally symmetric-Plan Buildings," SMIP92 Semin., 1992.

[26] O. M. O. Ramadan, S. S. F. Mehanny, and A. Mostafa, "Revisiting The 5\% Accidental Eccentricity Provision In Seismic Design Codes For Multi-Story Buildings," 14th World Conf. Earthq. Eng., 2008. 
[27] A. M. Chandler, J. C. Correnza, and G. L. Hutchinson, "Influence of accidental eccentricity on inelastic seismic torsional effects in buildings," Eng. Struct., vol. 17, no. 3, pp. 167-178, 1995, doi: 10.1016/0141-0296(94)00003-C.

[28] K. G. Stathopoulos and S. A. Anagnostopoulos, “Accidental design eccentricity : Is it important for the inelastic response of buildings to strong earthquakes ?," Soil Dyn. Earthq. Eng., vol. 30, no. 9, pp. 782-797, 2010, doi: 10.1016/j.soildyn.2009.12.018.

[29] D. J. DeBock, A. B. Liel, C. B. Haselton, J. D. Hooper, and R. A. Henige Jr, "Importance of seismic design accidental torsion requirements for building collapse capacity D.," Earthq. Eng. Struct. Dyn., vol. 43, no. 6, pp. 831-850, 2013, doi: 10.1002/eqe.

[30] S. A. Anagnostopoulos, M. T. Kyrkos, A. Papalymperi, and E. Plevri, "Should accidental eccentricity be eliminated from Eurocode 8?," Earthq. Struct., vol. 8, no. 2, pp. 463-484, 2015, doi: 10.12989/eas.2015.8.2.463.

[31] S. Anagnostopoulos and K. Stathopoulos, "Inelastic Earthquake Response of Buildings Subjected To Torsion," Proc. 12th World Conf. Earthq. Eng. Auckland, New Zeal., vol. Paper No., pp. 1-8, 2000.

[32] J. L. Lin, W. C. Wang, and K. C. Tsai, "Suitability of using the torsional amplification factor to amplify accidental torsion," Eng. Struct., vol. 127, pp. 1-17, 2016, doi: 10.1016/j.engstruct.2016.08.042.

[33] D. Basu, M. C. Constantinou, and A. S. Whittaker, "An equivalent accidental eccentricity to account for the effects of torsional ground motion on structures," Eng. Struct., vol. 69, pp. 1-11, 2014, doi: 10.1016/j.engstruct.2014.02.038. 